\title{
De-escalation treatment of axilla in breast cancer
}

\author{
G. Corso ${ }^{1,2} \oplus \cdot$ V. Galimberti $^{1} \cdot$ P. Veronesi ${ }^{1,2}$
}

Received: 29 March 2019 / Accepted: 26 April 2019 / Published online: 9 May 2019

(c) Federación de Sociedades Españolas de Oncología (FESEO) 2019

In cases of negative axillary staging, axillary lymph node dissection (ALND) has been replaced by sentinel node (SN) biopsy as the standard treatment for BC. ALND following a positive SN biopsy is being progressively abandoned. Results from the latest 10 years, phase 3 trial (IBCSG 23-01) confirmed that if the SN displays only micrometastases, then ALND is not indicated [1]. However, ALND is routinely performed in cases of macrometastatic SN biopsy, in particular after mastectomy. In breast-conserving surgery (BCS), results from the ACOSOG Z0011 trial contraindicated ALND if only one to two SNs are positive. ALND is still recommended if $\geq 3$ SNs contain metastases or macroscopic lymph node is found intraoperatively [2].

The AMAROS trial demonstrated that in patients with cT1-T2 primary $\mathrm{BC}$ with a positive $\mathrm{SN}$, axillary radiotherapy provides comparable, excellent axillary control as ALND. Further, not all patients need axillary radiotherapy, since similar excellent outcomes were described in the absence of axillary treatments (Fig. 1) [3].

Additional ongoing trials may indicate that even SN biopsy could be avoided in BCS in patients with small BC (tumor volume $\leq 2 \mathrm{~cm}$ in diameter) and negative preoperative ultrasound of the axilla [4].

The prospective randomized SENOMAC trial includes clinically node-negative $\mathrm{BC}$ patients with up to two macrometastases in their SN biopsy after mastectomy. Randomization will be between ALND vs. no ALND [5]. The final results from these two studies are awaited.

Interestingly, we are observing a progressive undertreatment of axilla during $\mathrm{BC}$ care, without great challenges in the treatment of the primary tumor, because adjuvant therapies are mostly proposed in accordance with cT staging and receptor status. Instead, SN involvement represents "only" a prognostic indicator.
G. Corso

giovanni.corso@ieo.eu

1 Division of Breast Surgery, European Institute of Oncology IRCCS, Via Ripamonti, 435, 20141 Milan, Italy

2 Faculty of Medicine, University of Milan, Milan, Italy 
Fig. 1 The panels show different conditions of SNs status. Black, gray and dashed spots represent, respectively, macrometastatic, micrometastatic and unknown pathology of axillary lymph nodes. Panel 1: breastconserving surgery. a In case of one/two macrometastatic SNs and micrometastasis, ALND is not indicated. $b$ In case of $\geq 3$ macrometastasis affecting SNs, ALND is recommended. Panel 2: mastectomy. c ALND is not the gold standard treatment after SN micrometastasis, and axillary lymph nodes should be preserved. d ALND is routinely performed when macrometastasis affects almost one $\mathrm{SN}$

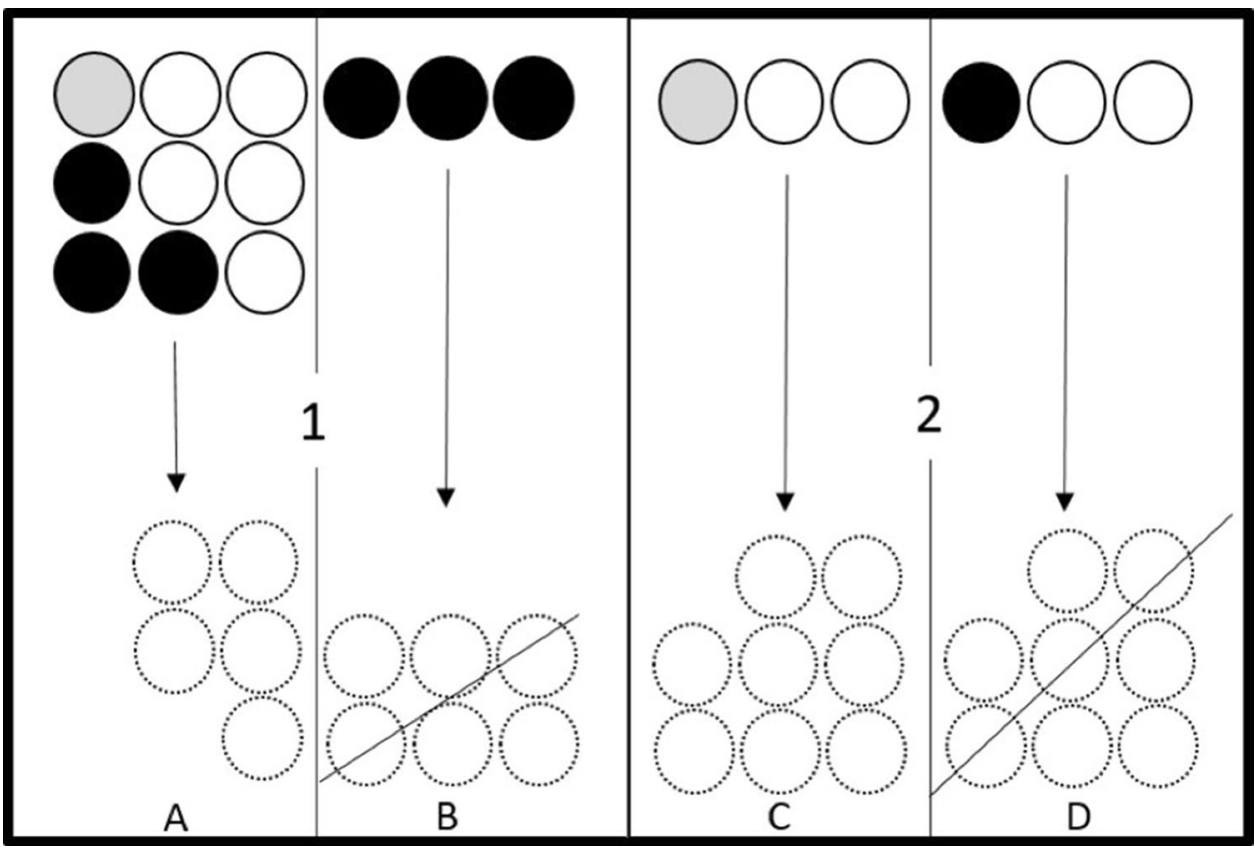

The past SN biopsy policy was no further axillary treatment if SNs were negative. To date, the new policy is changing to no additional axillary surgery if SNs are positive, but only the primary breast surgery. In future, no more SN biopsy?

\section{Compliance with ethical standards}

Conflict of interest The authors declare no competing interests.

Ethical approval This article does not contain any studies with human participants performed by any of the authors.

Informed consent For this type of study formal consent is not required.

\section{References}

1. Galimberti V, Cole BF, Viale G, et al. Axillary dissection versus no axillary dissection in patients with breast cancer and sentinel-node micrometastases (IBCSG 23-01): 10-year follow-up of a randomised, controlled phase 3 trial. Lancet Oncol. 2018;19(10):1385-93. https://doi.org/10.1016/S1470 $-2045(18) 30380-2$.
2. Giuliano AE, Ballman KV, McCall L, et al. Effect of axillary dissection vs no axillary dissection on 10-year overall survival among women with invasive breast cancer and sentinel node metastasis: the ACOSOG Z0011 (Alliance) randomized clinical trial. JAMA. 2017;318(10):918-26. https://doi.org/10.1001/ jama.2017.11470.

3. Donker M, van Tienhoven G, Straver ME, et al. Radiotherapy or surgery of the axilla after a positive sentinel node in breast cancer (EORTC 10981-22023 AMAROS): a randomised, multicentre, open-label, phase 3 non-inferiority trial. Lancet Oncol. 2014;15(12):1303-10. https://doi.org/10.1016/S1470 $-2045(14) 70460-7$.

4. Gentilini O, Botteri E, Dadda P, et al. Physical function of the upper limb after breast cancer surgery. Results from the SOUND (Sentinel node vs. Observation after axillary Ultra-souND) trial. Eur J Surg Oncol. 2016;42(5):685-9. https://doi.org/10.1016/j. ejso.2016.01.020.

5. de Boniface J, Frisell J, Andersson Y, et al. Survival and axillary recurrence following sentinel node-positive breast cancer without completion axillary lymph node dissection: the randomized controlled SENOMAC trial. BMC Cancer. 2017;17(1):379. https:// doi.org/10.1186/s12885-017-3361-y.

Publisher's Note Springer Nature remains neutral with regard to jurisdictional claims in published maps and institutional affiliations. 